\title{
DESARROLLO LOCAL Y PLANEACIÓN PARTICIPATIVA: ESCENARIOS PARA REINVENTAR EL DESARROLLO HUMANO DESDE EL TRABAJO SOCIAL* Arizaldo Carvajal Burbano**
}

\begin{abstract}
RESUMEN
En esta ponencia se parte de la hipótesis que el desarrollo local y la planeación participativa son escenarios para reinventar el desarrollo humano desde el trabajo social. El escrito se divide en cuatro partes: en la primera se plantea una discusión sobre el desarrollo en el marco de la relación local-global; luego se realizan unas articulaciones teóricas sobre desarrollo local y planeación participativa; la tercera parte intenta mostrar elementos para reinventar el desarrollo y la planeación desde el trabajo social. Y, finalmente, se aborda la temática del desarrollo humano, el crecimiento y la desigualdad, en los marcos planteados.
\end{abstract}

Palabra clave: Desarrollo, desarrollo local, desarrollo humano, planeación participativa, trabajo social.

\begin{abstract}
This report leaves of the hypothesis that the local development and the plan participating are scenarios to reinvent the human development from the social work. The writing is divided in four parts: in the first one he thinks about a discussion on the development in the mark of the local-global relationship; then they are carried out some theoretical articulations on local development and plan participating; the third part tries to show elements to reinvent the development and the planning from the social work. And, finally, the thematic of the human development, the growth and the inequality is approached, in the outlined marks.
\end{abstract}

Keywords: Development, local development, human development, plan participating, social work.

Ponencia presentada en el $33^{\circ}$. Congreso Mundial de Escuelas de Trabajo Social, cuyo tema central fue Crecimiento y desigualdad:Escenarios y desafíos para el trabajo social del siglo XXI, Santiago de Chile, Agosto de 2006.

Sociólogo y Especialista en Teoría y Métodos de Investigación de la Universidad del Valle. Magíster en Cooperación Internacional para el Desarrollo y Candidato a Doctor en Antropología Social por la Universidad Complutense de Madrid. Profesor de la Escuela de Trabajo Social y Desarrollo Humano de la Universidad del Valle, Cali -Colombia. Correo electrónico: aricarvajal@yahoo.es 


\section{PRESENTACIÓN}

“... de allí que nuestro primer y desesperado esfuerzo ha de ser el de encontrarnos con nosotros mismos y convencernos, además, de que el mejor desarrollo al que podemos aspirar será el desarrollo de países y culturas capaces de ser coherentes consigo mismas".

Manfred Max-Neef et al, Desarrollo a Escala Humana

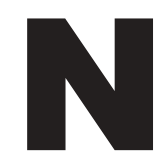

o podemos desconocer que en el mundo actual asistimos a profundos cambios en todos los niveles: en las formas tecnológicas; en las relaciones de poder; en la organización de la sociedad; en la mirada sobre el saber y los discursos; en los nuevos medios de comunicación y en la información; en el sistema de valores; en el papel de la familia; en los comportamientos y actitudes de los individuos; en las concepciones sobre el desarrollo y la planificación; en nuevas construcciones de identidades; en diferentes miradas sobre el crecimiento, la pobreza y la desigualdad; en nuevas visiones sobre el trabajo social, etc.

La globalización se da como un hecho; pero también el rescate de lo local, del lugar. Es el relanzamiento de lo local en la era de lo global. Siguiendo a Giddens (2000), la globalización influye en la vida diaria tanto como en los acontecimientos que se suceden a escala mundial. La globalización no tiene que ver sólo con lo que hay "ahí fuera", remoto y alejado del individuo. Es también un fenómeno de "aquí dentro", que influye en los aspectos íntimos y personales de nuestras vidas. La globalización es asible en lo pequeño y lo concreto, in situ, en la propia vida y en los símbolos culturales. Existe una relación entre lo local y lo global; son dos caras de un proceso. Según Kisnerman (1998), lo local nos plantea el desafío de mantener una apertura total a lo particular y una capacidad de análisis de las formas de inscripción de lo universal en lo particular, cuidando de no caer "tanto en las euforias localistas como en los determinismos estructuralistas".

En este nuevo siglo hay una reconfiguración del trabajo social (Vélez, 2003), una apuesta por nuevos escenarios de intervención o de actuación profesional. En esta ponencia se parte de la hipótesis que el desarrollo local y la planeación participativa son escenarios para reinventar el desarrollo humano desde el trabajo social; en un contexto de búsquedas de modelos realmente alternativos de desarrollo, construyendo democracia, constituyendo nuevos sujetos sociales y políticos, tejiendo nuevos vínculos sociales, nuevas narrativas y de relaciones con el otro, y como trabajadores y trabajadoras sociales, construyendo una verdadera poética de la alteridad.

El escrito se divide en cuatro partes: en la primera se plantea una discusión sobre el desarrollo en el marco de la relación local-global; luego se realizan unas articulaciones teóricas sobre desarrollo local y planeación participativa; la tercera parte intenta mostrar elementos para reinventar el desarrollo y la planeación desde el trabajo social. Y, finalmente, abordamos la temática del desarrollo humano, el crecimiento y la desigualdad, en los marcos planteados. 


\section{EL DESARROLLO EN EL MARCO DE LA RELACIÓN LOCAL-GLOBAL}

\section{La invención del desarrollo}

Comparto con Bernardo Kliksberg y Luciano Tomassini (2000), que "el debate sobre el desarrollo se ha reabierto a inicios del nuevo siglo. Hay más interrogantes y perplejidades que respuestas sólidas". Hay que señalar que el concepto de desarrollo es polémico, polisémico y dinámico; y se ha prestado a multiusos y también para abusos. Como cualquier otro concepto, el desarrollo es una construcción social e histórica. En este sentido, el concepto alude a un proceso de articulación social que abarca los ámbitos material, socio-político y cultural. Su contenido queda definido a partir de los medios, necesidades y valores que tiene una sociedad, por tanto es histórico" (León). Así, "considerar el desarrollo como una construcción social e histórica es reconocer que es un producto contingente y, por lo tanto, puede ser modificado" (Monreal y Gimeno, 1999).

Una mirada al desarrollo como "una construcción social”, lleva a reflexionar a Omar de León (1996) en torno a la propia idea de desarrollo, haciendo tres cuestionamientos: en primer término la idea que señala a la técnica como única condición necesaria para el desarrollo. La segunda cuestión, más general, se refiere a la concepción del desarrollo a partir de la experiencia histórica de los países que hoy llamamos desarrollados y de la conversión de su situación social actual en paradigma o modelo a seguir. Y en tercer lugar replantear la idea del desarrollo como proceso lineal relacionado con la idea de progreso. En esta misma línea, Gilbert Rist (2002) también mira el desarrollo como "una construcción de quien lo observa". Las representaciones que se asocian con él y las prácticas que implica varían radicalmente según se adopte el punto de vista del "desarrollador", comprometido en hacer llegar la felicidad a los demás, o el del "desarrollado", obligado a modificar sus relaciones, sociales y con la naturaleza, para entrar en el mundo nuevo que se le promete.

Es importante la definición de la palabra “desarrollo”. Señala Rist que el principal defecto de la mayoría de las pseudodefiniciones del "desarrollo" se debe a que están basadas, por lo general, en la manera en que en una persona (o un conjunto de personas) se presenta (n) las condiciones ideales de la existencia social. Esta forma de definir tiene la inmensa ventaja de reunir, sin mucho esfuerzo, un amplio consenso a partir de valores indiscutibles. No obstante, jsi el "desarrollo" no es más que un término cómodo para reunir al conjunto de las virtuosas aspiraciones humanas, puede llegarse inmediatamente a la conclusión de que no existe en parte alguna y de que, probablemente, no existirá jamás!Y, sin embargo, el "desarrollo" existe, en cierta manera, a través de las acciones que legitima las instituciones a las que hace vivir y los signos que atestiguan su presencia.

Desde la sociología del desarrollo es interesante la proposición de Guy Bajoit (1996) de replantear el desarrollo, considerándolo no como un proceso de cambio social, sino como un modo de 
comportamiento de la sociedad. Desarrollarse es aumentar la capacidad para resolver los problemas de la vida colectiva de una manera eficaz y éticamente aceptable.

Dentro de esta construcción es básica la concepción de la centralidad del sujeto, que se reclama como principio orientador de cualquier proyecto de desarrollo. En este enfoque lo importante es la gente, no las cosas. Durante mucho tiempo el predominio de lo económico y de la visión economicista del desarrollo ha propiciado el olvido de los aspectos humanos, culturales y ambientales que ahora tratan de recuperarse.

Para Escobar (2002) la idea del desarrollo está perdiendo fuerza, por su incapacidad para cumplir sus promesas, y hay que "contribuir a colocar en un primer plano y a posibilitar modos de vida y construcciones de identidad alternativas, marginales y disidentes. En este proceso, quizá el "desarrollo" dejará de existir como el objetivo incuestionado que ha sido hasta el presente"

No nos atrevemos a dar una definición precisa -o real- de desarrollo; su mismo carácter de invención lo impide. Coincidimos con Goulet (1999) que se necesita un concepto de desarrollo totalmente diferente, que se derive del interior de los diversos sistemas de valores que abrigan las comunidades vivas. Desde el corazón de estos valores, de estas redes de significados, de lealtades y de modelos de vida, es como deben definirse los fines propios del desarrollo y los medios más adecuados para conseguirlos.

\section{La relación local-global}

Sí, por todas partes escuchamos los mensajes de que estamos en la "era de la globalización". Pero, como expresábamos, hay que tener en cuenta que la globalización es asible en lo pequeño, en lo local. Para Barcellona (1996), la comunidad no es "nostalgia". Se requiere la comunicación con el otro, como base necesaria para la confirmación de la identidad. Es "la búsqueda de un terreno común más allá de la abstracción mutiladora del universalismo”.

"Lo pequeño es hermoso", no para encerrarse en ello, sino para poder aprehenderlo y moverse con soltura y confianza, para poder adecuarlo a las necesidades específicas de cada sujeto y de cada grupo humano; y desde esa relación de calidad poder abrirse a otras realidades más amplias (Villasante, 1998:18).

Aquí también es básico ver lo glocal (neologismo resultado de la fusión de las palabras global y local), que pretende reflejar la interpenetración entre ambas dinámicas. Pero, como lo expresa Moreno, la perspectiva "glocalística”, adquiere su más pleno significado y su mayor utilidad si no la entendemos simplemente en el sentido de que lo local sea un aspecto o una concreción a pequeña escala de lo global, sino, sobre todo, como un método de penetrar en la interrelación entre las dos dinámicas opuestas, pero complementarias y en modo alguno incompatibles, de la globalización y la localización (...) En lugar de seguir proponiendo "pensar globalmente y actuar 
localmente", como ha venido siendo norma obligada de la ciencia y el pensamiento occidentales durante los últimos dos siglos, tanto en su versión liberal como "socialista", la perspectiva glocalística propone algo diferente, que consiste en pensar, analizar y actuar glocalmente (Moreno, 1999:110,135). En palabras de Escobar (2000), es colocar una atención igual a la localización de lo global y a la globalización de lo local. El quid de la cuestión aquí sería distinguir aquellas formas de globalización de lo local que se transforman en fuerzas políticas efectivas en defensa de los lugares y de las identidades centradas en ellos, así como aquellas formas de "localización" de lo global que los locales pueden utilizar para sus propios fines. En otras palabras, es "desenredar lo global para enredar lo local"; es una visión de la globalización no "globalocéntrica”, sino desde la perspectiva de los lugares y de lo local.

Lo local convertido en global debe adaptarse a los diversos contextos locales para ser aceptado. Es preciso tener claro que los procesos de reafirmación cultural e identitaria no están reñidos con la asunción y el uso, sobre todo instrumental, de elementos culturales, incluyendo los tecnológicos, que sí están ya hoy globalizados. Antes al contrario, éstos están siendo asumidos y utilizados, crecientemente, desde estrategias locales, sin que ello signifique rehusar a la identidad y los valores culturales propios, sino como instrumentos de resistencia y de reafirmación de lo local, es decir, de lo específico.

\section{DESARROLLO LOCAL Y PLANEACIÓN PARTICIPATIVA: ARTICULACIONES TEÓRICAS}

\section{Sobre el desarrollo local}

En la mayoría de discursos sobre el desarrollo la dimensión local está presente; en cierta medida el desarrollo local es mirado como otra "moda del desarrollo". El debate sobre el desarrollo local es significativo, sea como resistencia a la globalización neoliberal, o como nicho de mercado para integrarse a la deseada era global; o como un modelo de desarrollo alternativo. Lo cierto es que en torno al desarrollo local hay muchos y complejos interrogantes.

Es necesario señalar que el paradigma de desarrollo local que sigue perfilándose en el siglo XXI no es un fenómeno exclusivamente europeo, sino global; las características y necesidades de la etapa actual del sistema económico mundial -la denominada globalización-, junto con la sucesión de fracasos de anteriores paradigmas y grandes programas de desarrollo, han favorecido la adopción de otros esquemas basados en el ámbito local (Pérez del Olmo, 2000).

Hay que anotar que muchas localidades, organizaciones e instituciones de Colombia y de América Latina "están enfrentadas al reto del desarrollo local como una de las opciones estratégicas de nuestro tiempo" y "el desarrollo local aparece como una nueva forma de mirar y de actuar desde el territorio en este nuevo contexto de globalización. Desde este punto de vista el desafío para las sociedades locales está planteado en términos de insertarse en forma competitiva en lo global, 
capitalizando al máximo sus capacidades locales y regionales a través de las estrategias de los diferentes actores en juego" (CLAEH, 2002).

El desarrollo local supone la circunscripción del desarrollo a un espacio "local" determinado. Para Fabio Velásquez, hablar de desarrollo local es aludir a "ese conjunto de procesos económicos, sociales, culturales, políticos y territoriales a través de los cuales una comunidad, a partir de sus propias potencialidades y de las oportunidades que le brinda el entorno, accede al bienestar, sin exclusiones ni discriminaciones, y garantiza las condiciones para que futuras generaciones también puedan hacerlo" (Velásquez, 1998:136). Siendo reiterativos, Esperanza Gómez define el desarrollo local como "un modelo de carácter teórico y metodológico que se promueve como alternativa para la gestión del desarrollo en un territorio físico espacial y específico, en el que coexisten actores, procesos y recursos entre dinámicas múltiples y complejas de tipo económicas, sociales, políticas y culturales, cuya finalidad es que lleguen a ser autopropulsivos y contribuyan efectivamente a mejorar las condiciones de vida de la sociedad local” (Gómez, 2005: 67). Así, los elementos o dimensiones constitutivas para la construcción de una perspectiva latinoamericana de desarrollo local serían cuatro: la dimensión territorial, las identidades o dimensión cultural, la dimensión política y la dimensión económica. La dinámica territorial y la orientación democrática que se le impriman al proceso dependerán de la capacidad de concertación de los actores locales.

Mientras que las teorías y políticas del desarrollo concentrador señalan el crecimiento cuantitativo y la maximización del producto interno bruto como guías del desarrollo, las estrategias de desarrollo local muestran un mayor interés y preocupación por la satisfacción de las necesidades básicas en el territorio, la mejora del empleo, ingreso y calidad de vida, así como el mantenimiento de la base de los recursos naturales y medioambientales.

\section{La planeación participativa}

La planeación ha sido un tema central en los discursos y las prácticas del desarrollo en general y del desarrollo local en particular. La planificación es considerada como una herramienta vital para pensar y crear el futuro. En general, para Carlos Matus, "planificar significa pensar antes de actuar, pensar con método, de manera sistemática (...) O sabemos planificar o estamos obligados a la improvisación (...) La planificación no es otra cosa que el intento del hombre por gobernar su futuro, por imponer la razón humana sobre las circunstancias" (citado por Huertas, 1994).

En alusión explícita a la planeación participativa, Velásquez y González (2003) comentan que ésta "es a la vez proceso y escenario". Como proceso comprende una serie de dinámicas sociales y políticas en torno a la identificación de problemas y potencialidades del presente y a la formulación de apuestas de futuro. Como escenario la planeación es una oportunidad de encuentro entre voces diferentes interesadas en construir consensos básicos sobre metas de bienestar y sobre los procedimientos, instrumentos y acciones necesarios para alcanzarlas. Es, en consecuencia, un 
proceso y un escenario eminentemente político que enlaza medios y fines, presente y futuro, problemas y soluciones, potencialidades y realizaciones, conocimiento y acción.

En la planificación se conjugan aspectos técnicos y políticos. En varios países y localidades de América Latina se ha hecho énfasis en la dimensión técnica del proceso, descuidando los aspectos políticos y culturales del mismo. La planificación se apoya en prácticas consideradas racionales u objetivas, "pero que son en realidad altamente ideológicas y políticas". Y, como lo expresa Escobar (1998), la ciencia y la planificación son vistos como neutrales, deseables y universalmente aplicables; mientras, en verdad, se estaba transfiriendo una experiencia civilizatoria entera y una particular racionalidad al Tercer Mundo mediante el proceso del “desarrollo". Se estaba asegurando un funcionamiento del poder.

La planificación participativa hace hincapié en situar a los ciudadanos en el centro de las decisiones. Aquí se utiliza el término "participación” en su sentido más amplio, para incluir aquellos procesos de transparencia, apertura, de toma de decisiones, de "dar voz" tanto en escenarios públicos como corporativos. Así, desde una perspectiva integral de desarrollo, la participación no se refiere únicamente al hecho de votar. Los procesos participativos comprenden el diálogo abierto, así como el amplio y activo compromiso ciudadano (Carvajal, 2005b).

Durante muchos años se ha venido discutiendo la relación entre democracia y desarrollo, de la importancia de la participación en estos procesos. Diversas experiencias -en desarrollo localmuestran que los procesos ampliamente participativos (de "dar voz", apertura y transparencia) promueven un desarrollo a largo plazo verdaderamente exitoso. Esto no significa que dichos procesos garanticen el éxito o que no existan riesgos inherentes a dichos procesos; significa, en cambio, "que el comprender la importancia que tienen los procesos abiertos, transparentes y participativos para el desarrollo, nos ayuda a diseñar políticas -estrategias y procesos- con mayores posibilidades de conducir al crecimiento económico a largo plazo y a reforzar las virtudes de los procesos mismos" (Stiglitz, 2000). La planeación participativa es un paso importante para construir una verdadera democracia local. Pero, como añade Escobar, "la planificación 'participatoria' o de nivel local, en realidad, es más frecuentemente concebida no en términos de un poder popular que la gente pueda ejercer, sino como un problema burocrático que la institución del desarrollo debe resolver" (Escobar, 1998).

Alvaro Obando (2003) ahonda en los sentidos sociales y políticos de la planeación participativa. Expresa que los sentidos de la planeación participativa como propuestas de la ciudadanía, parten de entender que ésta es un proceso de construcción social con características de continuidad y sostenibilidad, que busca la identificación, la explicación y la orientación de las transformaciones producidas y también las pretendidas para la ciudad, las comunas y las zonas. El hecho de que la planeación participativa sea un escenario estratégico para las comunidades y organizaciones sociales, donde convergen diversos intereses y motivaciones, hace que en ella, concurran miradas y expectativas variadas; a lo que se le suma la compleja realidad de las comunidades y zonas con sus 
problemáticas estructurales y contextuales del desarrollo y a la vez elementos potenciadores del mismo.

\section{REINVENTAR EL DESARROLLO Y LA PLANEACIÓN: UN RETO PARA EL TRABAJO SOCIAL}

En el primer apartado se presentó una visión del desarrollo como invención ("que no equivale a tacharlo de mentira, mito o conspiración"), producto de procesos históricos bien identificables, como una construcción social y cultural. Considerar el desarrollo como una invención "también sugiere que esta invención puede "desinventarse" o reinventarse de modos muy distintos" (Carvajal, 2005a).

El trabajo social (o mejor, los y las trabajadoras sociales) tiene el reto de inventar un desarrollo local con rostro humano; un desarrollo que vaya más allá del desarrollo económico o del crecimiento. Un desarrollo que prioriza el sujeto, el actor social, el ser; un "desarrollo a escala humana". Se resitúa el desarrollo más en el campo del ser que en el campo del tener. Hablando precisamente sobre subjetividad social y desarrollo humano, el sociólogo del PNUD, P. Güel, expresa que: "Un desarrollo que no promueve y fortalece confianzas, reconocimientos y sentidos colectivos, carece en el corto plazo de una sociedad que lo sustente. Entonces la viabilidad y éxito de un programa de desarrollo dependerá del grado en que las personas perciban ese programa como un escenario en que su subjetividad colectiva es reconocida y fortalecida" (citado por Boisier, 2003). Y, como lo señala la UNESCO, "un desarrollo disociado de su contexto humanocultural, es un desarrollo vacío, un desarrollo falaz e incompleto, un desarrollo sin alma".

En este marco, Obando (2003) plantea ocho estrategias de la planeación participativa: estrategia de formación de identidad; de formación de sujetos políticos; estrategia para la construcción propia del territorio; estrategia social y política para la construcción de lo público; para la superación de conflictos; para la gestión territorial del desarrollo; estrategia de inclusión y estrategia para la construcción de una política democrática. Estas son estrategias - podríamos decir de transformación social- que debe tener en cuenta el trabajador(a) social en su intervención en este campo, que "constituye un espacio de renovación permanente de los principios de la democracia; es, en ese sentido, una herramienta de pedagogía democrática para la formación de nuevos ciudadanos interesados en los asuntos públicos y conscientes de la importancia de contribuir a su definición. Además, reafirma los valores de la descentralización y de la autonomía política de los entes territoriales; propicia la cualificación de los líderes; crea condiciones para la densificación del tejido social; cambia los patrones de conducta de las administraciones municipales en el sentido de apertura a la iniciativa ciudadana, control social de la gestión pública, rendición de cuentas, asignación eficiente de los recursos y formulación de políticas públicas inclusivas" (Velásquez y González, 2003). 
Lo señalado anteriormente nos hace pensar que las propuestas de planes participativos de desarrollo, no sólo son construcciones internas de comunidades que optan por esta estrategia para transformar realidades concretas, sino que también son construcciones propias que se ponen en juego en contraposición a unos modelos excluyentes de desarrollo y a la vez tienen el ánimo de insertarse en ámbitos culturales e identitarios más globales (Obando, 2003).

Hay que reconocer que actuar en los campos del desarrollo y la planeación, es actuar en un escenario complejo; el desarrollo es un fenómeno complejo, un proceso dinámico, en construcción, lleno de significados. Y esto implica una mirada -y una intervención- amplia, llena de matices. Como lo expresa Duque (2004), un análisis de este tipo sólo es posible recuperando esas "historias no narradas" y reconociendo esos "espacios simbólicos" que definen "huellas proximales", para la redefinición del Trabajador Social como actor vital, en tanto re-definición del Trabajo Social como profesión compleja, y para un mundo complejo que, necesariamente hoy, ya no es conciliable frente a una praxis profesional desde visiones reduccionistas. Entre tanto, se puede observar que la mirada compleja al sistema de representaciones simbólicas de esta realidad, parte de insertar al Trabajador Social como su epicentro y de reconocerlo como texto social que, en condición de obra abierta, se presenta como una narración inacabada. Y estas narrativas podemos verlas en lo local, en los lugares, en la alternancia con la gente.

Es importante volver a la relación teoría-práctica, tanto en el campo del desarrollo como en cualquier otro campo. Recordemos que,

Hacer trabajo social es construir sujetos, personas, grupos, comunidades que en su hacer juntos, en su transformar su mundo humano y material, se descubren como actores solidarios, eficaces, capaces de enriquecer sus vidas y de trascender sus límites, sus pobrezas de marginación y de exclusión, de ausencia de recursos materiales y de acción. Cuando esta teoría implícita se hace consciente, el hacer se hace reflexivo, el hacer genera un conocer, un conocer juntos, que puede dialogar o confrontar el conocer y el hacer de otros: el actor social se conoce a sí mismo en su acción, se define ante sí y ante otros, se afirma, se legitime y desarrolla su capacidad de defender, de reivindicar (Valdés, 1992).

En este sentido -agrega Valdés-, los profesionales que los integran, se acerca a la imagen de “actor reflexivo" que postula Shön: "un explorador, un jugador, un experimentador que vive una tensión constructiva entre una realidad y un posible, avanzando cautelosamente para asegurar la posibilidad de realización de su idea". 


\section{DESARROLLO HUMANO, CRECIMIENTO, DESIGUALDAD Y TRABAJO SOCIAL (A MODO DE CONCLUSIÓN)}

Es un lugar común decir que crecimiento no es sinónimo de igualdad; que el modelo de desarrollo neoliberal en muchos países del mundo ha concentrado la riqueza en unas pocas manos e incrementado la desigualdad. Que "el mundo se ha rendido al modelo universal, al paradigma y al discurso sobre el desarrollo dominantes". Y, como lo señala Tegegn (2000), "es precisamente la validez de este discurso lo que queremos explorar aquí: su ética y si responde o no a las preguntas que se plantea la humanidad".

A nivel general, se habla de unos "modelos dominantes" de desarrollo y de unos "modelos alternativos" de desarrollo. El llamado modelo neoliberal, que también se lo ha venido a nombrar como pensamiento único, consiste -panorámicamente- en la liberalización de la economía, una economía de mercado; sus principales núcleos temáticos son la modernización, competitividad, Estado mínimo, mundialización, contracción de lo público, mercado, primacía monetaria, desregulación, desarrollo tecnológico, empresa. Su correlato político lo expresan términos como individuo, equidad, sociedad civil, neocorporativismo, gobernabilidad, eficacia. Se trata de la construcción de una ideología, que no afecta exclusivamente al pensamiento económico, sino a la representación total de una realidad que afirma que el mercado es el que gobierna y el Gobierno, quien gestiona (Estefanía, 2001). Conocemos que estas "fábulas del mercado", este modelo neoliberal, ha sido cuestionado, ya que en muchas partes del mundo han agravado ciertos problemas económicos, políticos, sociales, ambientales, etc., y que la pobreza y las desigualdades han aumentado en los últimos años. Como lo señala Stiglitz (2002:30), "la globalización no ha conseguido reducir la pobreza, pero tampoco garantizar la estabilidad".

Los "modelos alternativos" reivindican la capacidad de los propios pueblos para decidir, orientar y manejar su propio desarrollo, esto es, un "desarrollo desde abajo", acorde a las culturas locales. Y es aquí donde teorías como el desarrollo local, el desarrollo endógeno, el etnodesarrollo, etc., adquieren gran importancia y significado.

No está de más señalar que no todo Plan o programa que se autodenomine alternativo es alternativo; o es la panacea. Ante cierto descrédito del desarrollo, por incumplir sus promesas, por aumentar la desigualdad, por bajar el nivel o calidad de vida de la población (tanto a nivel objetivo o mensurable como a nivel subjetivo o cualitativo), se ha asumido "adornar" el desarrollo con otras palabras que le quiten su carga negativa; es la figura de estilo denominada oxímoron'.

El mundillo del desarrollo no se ha quedado atrás, ya que además del "desarrollo cultural"

inventó el "desarrollo humano" o el "desarrollo sostenible” Estas manipulaciones de la lengua

${ }^{1} \mathrm{El}$ uso de la figura oximoron consiste en superponer dos términos contradictorios, ejemplo: "una guerra limpia", "partido único". 
tienen evidentemente como objetivo el camuflaje, anulando la negatividad asociada a uno de los términos, para reemplazarla por la valoración positiva que se le da al otro. Al darle el calificativo de "limpia", la guerra se torna más aceptable; acompañado del adjetivo "sostenible", el desarrollo aparece como milagrosamente reconciliado con el medio ambiente, cuya destrucción ha acelerado desde hace dos siglos. Transformado de pronto en "cultural”, se deduce que hará buenas migas con todas esas culturas exóticas que antes consideraba como obstáculos para seguir avanzando" (Rist, 2000:136).

Mirado el desarrollo como discurso, como lenguaje, esto nos muestra la "maleabilidad del desarrollo". Este lenguaje, añade Rist, no hace sino encubrir la carencia de reflexión sobre las prácticas sociales, pero hace posible mantener intactas la legitimidad y la necesidad del "desarrollo". Existe allí una especie de zona ciega que permite evitar la discusión sobre lo que está principalmente en juego.

Casi siempre los modelos de desarrollo - de cualquier tipo- se hacen aparecer como "promesa": promesa de una mejor calidad de vida, de un bienestar, de un aumento de ingresos... la promesa del "desarrollo". Cuando en Colombia (a principios de los 90), se impone "salvajemente" el modelo neoliberal, también habían muchas promesas: reducción de la pobreza, equidad, modernización del Estado (léase eficiente y no corrupto), fortalecimiento del capital humano y social, un país en progreso económico, social y cultural, en fin, "un país moderno, ad portas del desarrollo". Quince años después el panorama es otro. Para el año 2005, la población colombiana se calcula en 45 millones de habitantes; y en los últimos años ha habido un incremento de la pobreza y la desigualdad. Estudios recientes (Contraloría, PNUD, Universidad Nacional) nos ilustran la problemática: cerca del 70\% de la población (30 millones de personas) viven en condiciones de pobreza. Como lo expresa Libardo Sarmiento:

El deterioro en la calidad y nivel de vida de los sectores populares y los trabajadores en Colombia se agrava día a día. Esta es una sociedad tres cuartos. Mientras tres de cada cuatro ciudadanos son excluidos y viven en condiciones de pobreza, otro $25 \%$ goza de opulencia y concentra los beneficios del estilo de desarrollo" (Sarmiento, 2004:8).

Así, en Colombia el crecimiento, la distribución de la riqueza, se ha concentrado en pocas manos. Y, parafraseando a Quijano (2002), el desarrollo ha pasado de ser un sueño a convertirse en una pesadilla colectiva. Un modelo llamado de desarrollo alternativo persigue el crecimiento económico con una redistribución de la riqueza, potencia los recursos humanos, fomenta la solidaridad; en otras palabras, le apuesta a un desarrollo humano (por no decir, un desarrollo humano integral sostenible, palabras o nombres que sin contenido son huecas, retóricas). Le apuesta a mejorar la calidad de vida de la población. 
En estos procesos de desarrollo es importante la discusión sobre la calidad de vida. Este concepto está frecuentemente en boca tanto de planificadores y políticos como de los pobladores. En el llamado desarrollo a escala humana hay una mirada amplia sobre la calidad o nivel de vida. Sabemos que un desarrollo que vaya más allá del crecimiento facilita la "potenciación del ser humano". Es pertinente anotar que en el concepto actual de calidad de vida se presentan tanto dimensiones mensurables (objetivas), como otras de más incierta cuantificación (subjetivas), que no se pueden disociar. Max-Neef (1986) habla de necesidades humanas y satisfactores. Los satisfactores se inscriben en contextos históricos y culturales determinados -según países, regiones urbanas o rurales, etc-, que le confieren un grado de relativismo según las condiciones específicas creadas. La satisfacción de las necesidades está sujeta a los cambios de los satisfactores y, en consecuencia, a los cambios de las formas de acceso a la satisfacción de las necesidades. Lo interesante de este planteamiento es que nos lleva a una visión amplia de la llamada calidad de vida, teniendo en cuenta tanto las "necesidades existenciales" (ser, tener, hacer, estar) como las "necesidades axiológicas" (subsistencia, protección, afecto, comprensión, participación, creación, recreación, identidad y libertad). Ya no es común -¿`será que suena cursi?- ligar el concepto de desarrollo al de felicidad, que se supone es una de las máximas aspiraciones humanas.

Siendo reiterativos, no hay un solo desarrollo. Veíamos que hay diferentes paradigmas y modelos de desarrollo. Los nuevos paradigmas van más allá de ver el desarrollo solo como crecimiento económico. Recordemos que "cada tipo de desarrollo tiene el sello de la sociedad que lo vive", y si no, no es sostenible. Como observamos, hablar de desarrollo depende de cómo veamos el mundo. Sabemos que no hay modelos únicos. "Más aún, es posible recuperar el desarrollo como un espacio importante para reelaborar y trabajar la modernidad, para convertirla en algo distinto" (Escobar, 2002).

Decíamos que el desarrollo, en esencia, siempre está centrado en la gente. La gente es -y debe ser- el punto de partida, el centro y el propósito final de cada intervención tendiente al desarrollo. Pero los planificadores del proceso de desarrollo tradicionalmente poco o nada han tenido en cuenta a la gente. Así, lo común ha sido la aplicación de una planificación de "arriba hacia abajo", que no comprende - ni tiene en cuenta- a la población local, la cultura local. Muchos planes de desarrollo o planes de vida "carecen de un compromiso profundo para lograr el desarrollo". Como lo señala Mohan (1997), "del desarrollo centrado en la gente se ha hablado más de lo que se ha logrado en la práctica. A pesar de ello, sigue siendo un hecho que si el desarrollo ha de mejorar la calidad de vida para grandes segmentos de pobres del Tercer Mundo, éstos deben adquirir el derecho a participar en las decisiones que afectan su futuro". Esto implica algunos desafíos de gran envergadura para el trabajo social; implica "girar y enriquecer sus modelos de intervención social" (Matus, 2004).

En Colombia -y en otros países-, en una época de locura por la globalización neoliberal y de embrujos autoritarios, se hace indispensable pensar alternativas para nuevos modelos de desarrollo, 
para consolidar la democracia, para disminuir la pobreza y la desigualdad en uno de los países más inequitativos del mundo. El desarrollo local, como modelo alternativo de desarrollo, puede dinamizar procesos sociales que lleven a una sociedad más democrática y participativa; a la constitución de sujetos sociales y políticos, a un desarrollo con equidad y justicia social. Y en estos procesos, el trabajo social (desde una ética-política del desarrollo; desde una "poética de la alteridad") puede y debe jugar un papel fundamental.

\section{BIBLIOGRAFÍA CITADA}

BAJOIT, Guy (1996). "Replantear el desarrollo", publicado en la revista Antipodes No. 131, ITECO. BARCELLONA, Pietro (1996). Postmodernidad y comunidad. El regreso de la vinculación social, Madrid, Editorial Trotta.

BOISIER, Sergio (2003). “¿Y si el desarrollo fuese una emergencia sistémica?”, en Fabio GIRALDO (editor). Ciudad y complejidad, Bogotá, FICA.

CARVAJAL, Arizaldo (2005a). Desarrollo y cultura. Elementos para la reflexión y la acción, Cali, Escuela de Trabajo Social y Desarrollo Humano- Universidad del Valle.

CARVAJAL, Arizaldo (2005b). Planeación participativa: Diagnóstico, plan de desarrollo y evaluación de proyectos, Cali, Programa Editorial Facultad de Humanidades-Universidad del Valle.

CLAEH (Centro Latinoamericano de Economía Humana) (2002). La construcción del desarrollo local en América Latina. Análisis de experiencias, Montevideo, CLAEH-ALOP.

DUQUE, Aura Victoria (2004). Praxis, identidad y Formación en Trabajo Social. Un estudio del Sistema de Representaciones Simbólicas, Manizales, CONETS - Universidad de Caldas. Textos de Investigación en el Trabajo Social $N^{\circ} 1$.

ESCOBAR, Arturo (1998). La invención del Tercer Mundo. Construcción y deconstrucción del desarrollo, Santafé de Bogotá, Editorial Norma.

ESCOBAR, Arturo (2000). "El lugar de la naturaleza y la naturaleza del lugar: globalización o posdesarrollo", en Andreu Viola (compilador). Antropología del desarrollo. Teorías y estudios etnográficos en América Latina, Barcelona, Editorial Paidós.

ESCOBAR, Arturo (2002). "Globalización, desarrollo y modernidad”, en Arturo Escobar et al. Planeación, participación y desarrollo, Medellín, Corporación Región.

ESTEFANÍA, Joaquín (2001). La nueva economía. La globalización, Barcelona, Editorial Debate-Nuevas Ediciones de Bolsillo.

FURIÓ, Elies (1996). Evolución y cambio en la economía regional, Barcelona, Editorial Ariel.

GIDDENS, Anthony (2000). Un mundo desbocado. Los efectos de la globalización en nuestras vidas, Madrid, Taurus.

GIMENO, Juan Carlos y Pilar Monreal (eds) (1999). La controversia del desarrollo. Críticas desde la antropologia, Madrid, Los libros de la Catarata-IUDC/UCM.

GÓMEZ, Rubby Esperanza (2005). "El desarrollo local, desafío para el trabajo social contemporáneo", en Revista Trabajo social No. 2, Departamento de Trabajo social, Universidad de Antioquia, Medellín, Julio-Diciembre 2005.

GOULET, Denis (1999). Etica del desarrollo. Guía Teórica y Práctica, Madrid, IEPALA Editorial.

HUERTAS, Franco (1994). El método PES. Entrevista con Matus, Caracas, Fundación Altadir.

KISNERMAN, Natalio (1998). Pensar el trabajo social. Una introducción desde el construccionismo, Buenos Aires, LUMEN-HVMANITAS.

KLIKSBERG, Bernardo y Luciano Tomassini (Compiladores) (2000). Capital social y cultura: claves estratégicas para el desarrollo, Buenos Aires, FCE. 
LEÓN NAVEIRO, Omar de (1996). Economía informal y desarrollo. Teorías y análisis del caso peruano, Madrid, Los Libros de la Catarata-IUDC/UCM.

MATUS, Teresa (2004). "Escenarios y desafíos del trabajo social en América Latina", en Revista Colombiana de Trabajo Social No. 18, CONETS, Manizales, Marzo de 2004.

MAX-NEEF, Manfred et al (1986). Desarrollo a Escala Humana. Una opción para el futuro, Upsala, CEPAUR.

MOHAN MATUR, Hari (1997). "Desarrollo centrado en la gente", en KLIKSBERG, Bernardo (Compilador). Pobreza un tema impostergable. Nuevas respuestas a Nivel Mundial, Caracas, Fondo de Cultura Económica.

MORENO, Isidoro (1999). "Globalización, identidades colectivas y antropología”, en Francisco Fernández del Riego et al (coords). Las identidades y las tensiones culturales de la modernidad, Santiago de Compostela, VIII Congreso de Antropología, FAAEE/AGA.

OBANDO, Alvaro et al (2003). La planeación participativa. Una apuesta de ciudad, Medellín, Corporación Región.

PÉREZ, Bartolomé y Emilio Carrillo Benito (coord.) (2000). Desarrollo local: manual de uso, Madrid, ESIC.

QUIJANO VALENCIA, Olver (2002). De sueño a pesadilla colectiva. Elementos para una crítica políticocultural del desarrollo, Popayán, Editorial Universidad del Cauca.

RIST, Gilbert (2002). El desarrollo: historia de una creencia occidental, Madrid, Instituto Universitario de Desarrollo y Cooperación /Universidad Complutense de Madrid- Los libros de la Catarata.

SARMIENTO, Libardo (2004). "Balance Social del Gobierno Uribe”, en periódico Caja de Herramientas, Corporación Viva la Ciudadanía, Año 13 No. 101, Bogotá, Agosto de 2004.

STIGLITZ, Joseph (2000). "Participación y desarrollo: perspectivas desde el paradigma integral de desarrollo", en Revista Instituciones y Desarrollo No.7, Barcelona.

STIGLITZ, Joseph (2002). El malestar en la globalización, Santafé de Bogotá, Taurus.

TEGEGN, Melakou (2000). "El desarrollo y la influencia de los organismos de ayuda”, en INTERMÓN/ OXFAM. Desarrollo y Poder, Barcelona, Ediciones Octaedro.

VALDÉS, Ximena (1992). "Las cuentas pendientes de la sistematización”, en María de la Luz Morgan. Salud comunitaria y promoción del desarrollo. Módulo V: Sistematización de experiencias de trabajo en salud, Lima, CELATS.

VELÁSQUEZ, Fabio (1998). "Gobierno local y promoción del desarrollo. Una reflexión sobre el caso colombiano", en Gobiernos locales y desarrollo en América latina, Lima, USAID/ESAN.

VELÁSQUEZ, Fabio y Esperanza González (2003). ¿Qué ha pasado con la participación ciudadana en Colombia?, Bogotá, Fundación Corona.

VÉLEZ, Olga Lucía (2003). Reconfigurando el Trabajo Social. Perspectivas y tendencias contemporáneas, Buenos Aires, Espacio Editorial.

VILLASANTE, Tomás R (1998). Cuatro redes para Mejor-Vivir 1. Del desarrollo local a las redes para mejorvivir, Buenos Aires, Editorial LUMEN/HVMANITAS.

Recibido: Septiembre 13 de 2006

Aprobado: Septiembre 18 de 2006 